\title{
Passive leg cycling and electrical stimulation cannot preserve strength in sepsis
}

Pierre-François Laterre ${ }^{*}$, Cheryl Hickmann and Diego Castanares-Zapatero

This comment refers to the article available at: https://doi.org/10.1001/jama.2018.9592

Keywords: Critically ill, Exercise, Electrical stimulation, Muscle, Strength

To the Editor,

In a prospective, randomized, single-center trial including a total of 314 patients, Fossat et al. reported that early in-bed leg cycling exercises together with quadriceps muscles electrical stimulation added to standard rehabilitation program did not improve global muscle strength of critically ill patients at the time of intensive care unit (ICU) discharge [1]. Although the authors adequately pointed out the limitations of their study, the take-home message to critical care personnel may be misleading. Indeed, there are additional aspects in the intervention methods, baseline characteristics, and concomitant therapies that may have modified the observed results and conclusions.

First, passive cycling is unlikely to be able to stretch muscles and therefore no real benefit to muscle strength could be expected. In the study by Burtin et al., exercises using a cycle ergometer were in fact active in up to $87 \%$ of the sessions [2]. Second, the duration of this passive cycling was short. In our study, as sedative medication use was restricted, two 30-minute sessions of active/passive cycling were performed by our patients with septic shock and were associated with muscle mass preservation [3]. Third, more than $75 \%$ of the patients studied had continuous sedation and $20 \%$ had a continuous muscle relaxant infusion suspected to be associated with ICU-acquired weakness. Fourth, electric muscle stimulation has been shown to be ineffective in many critically ill patients, especially because of tissue edema and reduced motor response. In the studied population

\footnotetext{
* Correspondence: pierre-francois.laterre@uclouvain.be

This comment refers to the article available at: https://doi.org/10.1001/ jama.2018.9592

St Luc University Hospital, Université Catholique de Louvain, Avenue Hippocrate 12, 1200 Brussels, Belgium
}

presented by the authors, more than $60 \%$ had sepsis or shock and these conditions are known to be associated with a poor electric response $[4,5]$. In addition, the proportion of patients with sepsis was significantly greater in the intervention than in the usual-care group $(69 \%$ versus $56 \%, P=0.02$ ). Finally, the passive and active exercises applied in the usual-care group already represent an important intervention, and as pointed by the authors, a quarter of the patients had close to maximal expected muscle strength at discharge and a ceiling effect cannot be excluded.

In our opinion, the conclusion of the study should instead be that short-duration passive leg cycling and electrical quadriceps stimulation did not improve muscle strength in critically ill patients who have sepsis and who need prolonged sedation.

\section{Abbreviation \\ ICU: Intensive care unit}

\section{Acknowledgments}

Not applicable.

\section{Funding}

The authors declare that there was no funding pertaining to this letter.

\section{Availability of data and materials}

Not applicable.

\section{Authors' contributions}

All authors participated equally in writing the manuscript. All authors read and approved the final manuscript.

\section{Ethics approval and consent to participate Not applicable.}

\section{Consent for publication \\ Not applicable.}

\section{Competing interests}

The authors declare that they have no competing interests. 


\section{Publisher's Note}

Springer Nature remains neutral with regard to jurisdictional claims in published maps and institutional affiliations.

Received: 21 September 2018 Accepted: 10 October 2018

Published online: 08 February 2019

\section{References}

1. Fossat G, Baudin F, Courtes L, Bobet S, Dupont A, Bretagnol A, et al. Effect of In-Bed Leg Cycling and Electrical Stimulation of the Quadriceps on Global Muscle Strength in Critically III Adults: A Randomized Clinical Trial. JAMA. 2018;320:368-78.

2. Burtin C, Clerckx B, Robbeets $C$, Ferdinande $P$, Langer D, Troosters $T$, et al. Early exercise in critically ill patients enhances short-term functional recovery. Crit Care Med. 2009:37:2499-505.

3. Hickmann CE, Castanares-Zapatero D, Deldicque L, Van den Bergh P, Caty G, Robert A, et al. Impact of Very Early Physical Therapy During Septic Shock on Skeletal Muscle: A Randomized Controlled Trial. Crit Care Med. 2018;46:1436-43.

4. Segers J, Hermans G, Bruyninckx F, Meyfroidt G, Langer D, Gosselink R. Feasibility of neuromuscular electrical stimulation in critically ill patients. J Crit Care. 2014;29:1082-8.

5. Poulsen JB, Møller K, Jensen CV, Weisdorf S, Kehlet H, Perner A. Effect of transcutaneous electrical muscle stimulation on muscle volume in patients with septic shock. Crit Care Med. 2011;39:456-61. 